Journal of Mathematics and Statistics 7 (1): 51-56, 2011

ISSN 1549-3644

(C) 2010 Science Publications

\title{
Fuzzy Parametric Deduction for Material Removal Rate Optimization
}

\author{
Tian-Syung Lan \\ Department of Information Management, \\ Yu Da University Miaoli County, 361, ROC, Taiwan
}

\begin{abstract}
Problem statement: A general optimization scheme without equipment operations for CNC (computer numerical control) finish turning is deemed to be necessarily developed. Approach: In this study, four parameters (cutting depth, feed rate, speed, tool nose runoff) with three levels (low, medium, high) were considered to optimize the Material Removal Rate (MRR) based on $\mathrm{L}^{9}\left(3^{4}\right)$ orthogonal array. Twenty-seven fuzzy control rules using trapezoid membership function with respective to seventeen linguistic grades for material removal rate were additionally constructed. Considering thirty input and eighty output intervals, the defuzzification using center of gravity was moreover completed. Through the Taguchi experiment, the optimum fuzzy deduction parameters could then be received. Results: The confirmation experiment for optimum deduction parameters was furthermore computed within the parameter ranges on an ECOCA-3807 CNC lathe. It is shown that the material removal rate from the fuzzy deduction optimization parameters was significantly advanced comparing to that from the benchmark. Conclusions: This study not only proposed a parametric deduction optimization scheme using orthogonal array, but also contributed the satisfactory fuzzy approach to the material removal rates for $\mathrm{CNC}$ turning with profound insight.
\end{abstract}

Key words: Computer Numerical Control (CNC), Taguchi method, fuzzy deduction optimization, Material Removal Rate (MRR), CNC turning, deduction parameters, fuzzy linguistic, fuzzy control rules, control factors, design parameters, process parameters

\section{INTRODUCTION}

Machining operations have been the core of the manufacturing industry since the industrial revolution (Rao, 2006). The existing optimization researches for Computer Numerical Controlled (CNC) turning were either simulated within particular manufacturing circumstances (Sukontanakarn and Parnichkun, 2009; Lin et al., 2001; Haber et al., 2004; Meng et al., 2000) or achieved through numerous frequent equipment operations (Kopac, 2002; Tosun and Ozler, 2004). Nevertheless, these are regarded as computing simulations and the applicability to real world industry is still uncertain. Therefore, a general optimization scheme without equipment operations is deemed to be necessarily developed.

The machining process on a CNC lathe is programmed by speed, feed rate and cutting depth, which are frequently determined based on the job shop experiences. However, the machine performance and the product characteristics are not guaranteed to be acceptable. Therefore, the optimum turning conditions have to be accomplished. It is mentioned that the tool nose run-off will affect the performance of the machining process (Lan, 2010). Therefore, the tool nose run-off is also selected as one of the control factors in this study.
Material removal rate is commonly considered as a major manufacturing goal (Tosun and Ozler, 2004) for turning operations in many of the existing researches. Taguchi method, an experimental design method, has been widely applied to many industries. It can not only optimize quality characteristics through the setting of design parameters, but also reduce the sensitivity of the system performance to sources of variation (Huh et al., 2003; Nalbant et al., 2007; Ismail et al., 2009; Kim et al., 2003). The Taguchi method adopts a set of orthogonal arrays to investigate the effect of parameters on specific quality characteristics to decide the optimum parameter combination. These kinds of arrays use a small number of experimental runs to analyze the quality effects of parameters as well as the optimum combination of parameters.

To achieve the deduction optimization, it is necessary to first describe the dynamic behavior of the system to be controlled. Because of the number, complexity and unclear, vague nature of the variables of the dynamic systems that may influence the decision maker's decision, fuzzy set theory is the most suitable solution (Zadeh, 1965; Zimmerman, 2001). Fuzzy linguistic models permit the translation of verbal expressions into numerical ones (Gungor and Arıkan, 2007). Therefore, the input output 
relationship of the process can be described by the collection of fuzzy control rules involving linguistic variables rather than a complicated dynamic mathematical model.

With all the viewpoints above, this study considers four parameters (cutting depth, feed rate, speed, tool nose runoff) with three levels (low, medium, high) to optimize the MRR in CNC finish turning. The fuzzy control rules using trapezoid membership function with respective to seventeen linguistic grades for MRR are additionally constructed. The defuzzification is then quantified using center of gravity and introduced as the $\mathrm{S} / \mathrm{N}$ (signal-to-noise) ratio to Taguchi experiment and thus the optimum deduction parameters can then be received. This study definitely proposes a fuzzy deduction optimization approach and satisfactory fuzzy linguistic deduction technique for improving material removal rate in $\mathrm{CNC}$ turning with profound insight.

\section{MATERIALS AND METHODS}

In this study, the variable quantification and deduction optimization for $\mathrm{CNC}$ turning operations are proposed using fuzzy set theory and Taguchi method respectively. They are described as below.

Fuzzy set theory: Let $x$ be an universe of discourse, $\tilde{\mathrm{A}}$ is a fuzzy subset of $\mathrm{x}$ if for all $\mathrm{x \in X}$, there is a number $\mu_{\tilde{\AA}}(\mathrm{x}) \in[0,1] \quad$ assigned to represent the membership of $\mathrm{x}$ to $\tilde{\mathrm{A}}$ and $\mu_{\tilde{\mathrm{A}}}(\mathrm{x})$ is called the membership function of $\tilde{A}$. A trapezoid fuzzy number $\tilde{A}$ can be defined by a trip-let $(a, b, c, d)$ (Fig. 1) (Kaufmann and Gupta, 1991). The membership function is defined as:

$\mu_{\tilde{A}}(x: a, b, c, d)=\left\{\begin{array}{cl}\frac{x-a}{b-a} & a<x \leq b \\ 1 & b<x \leq c \\ \frac{x-d}{c-d} & c<x \leq d \\ 0 & \text { otherwise }\end{array}\right.$

In this study, the three most important parameters for the MRR are primarily concluded through literature review. Additionally, twenty-seven fuzzy control rules using trapezoid membership function with respective to seventeen linguistic grades will be constructed following IF-THEN rules.

To eliminate the computation, thirty input and eighty output intervals are considered to prepare the defuzzification. Through Cartesian product, the degree of membership for both input and output can thus be attained as:

$\mathrm{R}=$ Input*Output

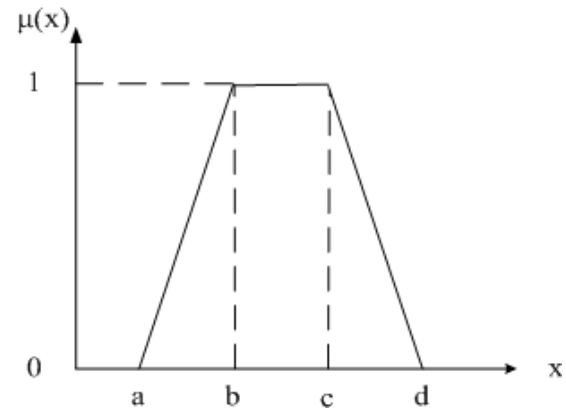

Fig. 1: Trapezoid fuzzy numbers

Here, "Input" describes the parameter, Output represents the attribute and $\mathrm{R}$ denotes the fuzzy relation between the parameter and attribute.

The "OR" rules are then utilized for combining rules for maximum degree of membership as:

$\mu \mathrm{R} 1+\mu \mathrm{R} 2=\max \{\mu \mathrm{R} 1, \mu \mathrm{R} 2\}$

where, 1-R2 symbolize for the two rules.

In this study, the average value using center of gravity is determined to represent the fuzzy set as:

$\mathrm{F}\left(\mathrm{x}_{\mathrm{i}}\right)=\frac{\sum_{\mathrm{i}} \mathrm{x}_{\mathrm{i}} * \mu_{\tilde{\mathrm{A}}}\left(\mathrm{x}_{\mathrm{i}}\right)}{\sum_{\mathrm{i}} \mu_{\tilde{\mathrm{A}}}\left(\mathrm{x}_{\mathrm{i}}\right)}$

where, $F\left(x_{i}\right)$ is the final rating of activity, $\mu_{\tilde{A}}\left(x_{i}\right)$ describes the membership function of fuzzy set $\tilde{A}$.

Taguchi method: The Taguchi method is a robust design method technique (Palanikumar, 2008; Ross, 1998), which provides a simple way to design an efficient and cost effective experiment. In order to efficiently reduce the numbers of conventional experimental tasks, the orthogonal array (Lan and Wang, 2009a; Wei et al., 2002) by using design parameters (control factors) in column and standard quantities (levels) in row is proposed and further adopted. The performance measure, signal-to-noise ratio (S/N) (Park et al., 2005) proposed by Taguchi is used to obtain the optimal parameter combinations. The larger $\mathrm{S} / \mathrm{N}$ means the relation to the quality will become better. The lower quality characteristic will be regarded as a better result when considering the smaller-the-best quality. The related $\mathrm{S} / \mathrm{N}$ ratio is defined as:

$\mathrm{S} / \mathrm{N}-10\left(\log \sum_{\mathrm{i}=1}^{\mathrm{n}} \frac{\mathrm{y}_{\mathrm{i}}^{2}}{\mathrm{n}}\right)(\mathrm{dB})$

Where: 
$\mathrm{n}=$ Number of experiments for each experimental set

$\mathrm{y}_{\mathrm{i}}=$ expresses the quality characteristic at the i-th experiment

On the contrary, the larger quality characteristic will have better result $t$ when considering the largerthe-best quality, therefore, by taking the inverse of quality characteristic into Eq. 5 , the related $\mathrm{S} / \mathrm{N}$ ratio can also be deduced and shown in Eq. 6:

$\left.\mathrm{S} / \mathrm{N}-10\left(\log \sum_{\mathrm{i}=1}^{\mathrm{n}} \frac{1 / \mathrm{y}_{\mathrm{i}}^{2}}{\mathrm{n}}\right) \mathrm{dB}\right)$

In this study, the defuzification result for MRR is introduced to the Taguchi experiment as the $\mathrm{S} / \mathrm{N}$ ratio. Therefore, it is judged as the quality of smallerthe-best. In addition to the $\mathrm{S} / \mathrm{N}$ ratio, a statistical Analysis Of Variance (ANOVA) (Wu and Chyu, 2002) can be employed to indicate the impact of process parameters. In this way, the optimal levels of process parameters can be estimated.

Research design: Material Removal Rate (MRR) is considered the major quality in this study. Four parameters with three levels are selected to optimize the MRR in finish turning based on the $\mathrm{L}_{9}\left(3^{4}\right)$ orthogonal array. Additionally, twenty-seven fuzzy control rules with respective to seventeen linguistic grades for the MRR are constructed. Considering thirty input and eighty output intervals, the defuzzification using center of gravity is thus completed for the Taguchi experiment and thus the optimum general deduction parameters can then be received.

Construction of orthogonal array: In this study, the four turning parameters (A-speed, B-cutting depth, C-feed rate and D-tool nose runoff ) (Lan and Wang, $2009 \mathrm{~b}$ ) with three different levels (low, medium and high) (Table 1) are constructed for the deduction optimization of machining operation. In Table 1, the three levels of speed, cutting depth and feed rate are considered according to the machining handbook suggested by the tool manufacturer. The tool nose runoff is positioned by using different shims located under the tool shank in the tool holder. The orthogonal array is then selected to perform the nine sets of deduction experiments.

The material removal rate can be expressed as MRR $=1000 \mathrm{fdv}$. As the experimental results (Sukontanakarn and Parnichkun, 2009) the surface speed (v) has the least effect to the MRR. Therefore, the depth of cut (d) and feed rate (f) are considered major parameters for MRR. The seven linguistic grades for MRR are determined as Table 2.

Defuzzification: In this study, the three parameter levels are selected based on the Taguchi experimental method, therefore, each triangle membership function is related to the peak point of its fuzzy area. Considering thirty input and eighty output intervals, the defuzzification of seventeen linguistic grades using center of gravity can then be completed.

\begin{tabular}{lllll}
\multicolumn{2}{l}{ Table 1: Orthogonal array } \\
\hline $\begin{array}{l}\text { Parameter } \\
\text { Experiment }\end{array}$ & A & $\begin{array}{l}\text { B } \\
\text { (cutting }\end{array}$ & $\begin{array}{l}\text { C } \\
\text { (feed rate) }\end{array}$ & $\begin{array}{l}\text { D } \\
\text { (tool nose } \\
\text { runoff) }\end{array}$ \\
\hline 1 & Low & Low & Low & Low \\
2 & Low & Medium & Medium & Medium \\
3 & Low & High & High & High \\
4 & Medium & Low & Medium & High \\
5 & Medium & Medium & High & Low \\
6 & Medium & High & Low & Medium \\
7 & High & Low & High & Medium \\
8 & High & Medium & Low & High \\
9 & High & High & Medium & Low \\
\hline
\end{tabular}

\begin{tabular}{lllll}
\multicolumn{5}{l}{ Table 2: Fuzzy rules for material removal rate } \\
\hline Rules & Feed rate & Cutting depth & Speed & Deduction \\
\hline 1 & Low & Low & Low & smallest \\
2 & Low & Low & Medium & super small \\
3 & Low & Low & High & small small \\
4 & Low & Medium & Low & super small \\
5 & Low & Medium & Medium & large \\
6 & Low & Medium & High & much smaller \\
7 & Low & High & Low & smaller \\
8 & Low & High & Medium & a little smaller \\
9 & Low & High & High & a little larger \\
10 & Medium & Low & Low & small small \\
11 & Medium & Low & Medium & smaller \\
12 & Medium & Low & High & a little smaller \\
13 & Medium & Medium & Low & much smaller \\
14 & Medium & Medium & Medium & medium \\
15 & Medium & Medium & High & much larger \\
16 & Medium & High & Low & a little larger \\
17 & Medium & High & Medium & larger \\
18 & Medium & High & High & large large \\
19 & High & Low & Low & a little smaller \\
20 & High & Low & Medium & a little larger \\
21 & High & Low & High & larger \\
22 & High & Medium & Low & much larger \\
23 & High & Medium & Medium & large \\
24 & High & Medium & High & super large \\
25 & High & High & Low & large large \\
26 & High & High & Medium & extreme large \\
27 & High & High & High & largest \\
\hline & & & &
\end{tabular}




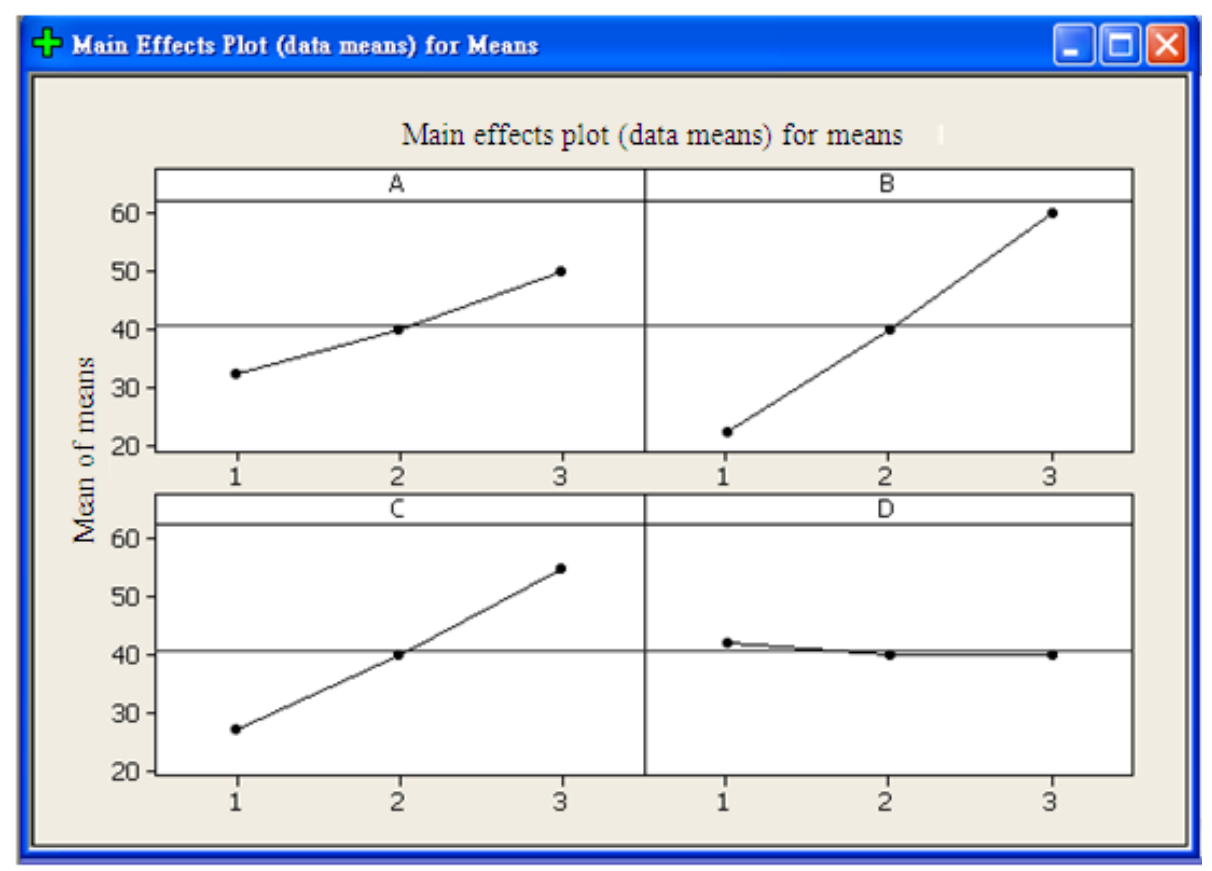

Fig. 2 : Plot of main effects

Table 3: Trapezoid ranges of three linguistic levels for parameters

\begin{tabular}{llll}
\hline Linguistic level & Low & Medium & High \\
\hline Range & {$[0,12.5,15]$} & {$[0,2.5,27.5,30]$} & {$[15,17.5,30]$} \\
\hline
\end{tabular}

Table 4: Trapezoid ranges of seventeen linguistic levels for attributes

\begin{tabular}{llllll}
\hline Linguistic level & Smallest & Extreme small & Super small & Small small & Small \\
\hline Range & {$[0,2.5,5]$} & {$[0,2.5,7.5,10]$} & {$[5,7.5,12.5,15]$} & {$[10,12.5,17.5,20]$} & {$[15,17.5,22.5,25]$} \\
Smaller & Much smaller & A little smaller & Medium & A little larger & Much larger \\
{$[20,22.5,27.5,30]$} & {$[25,27.5,32.5,35]$} & {$[30,32.5,37.5,40]$} & {$[35,37.5,42.5,45]$} & {$[40,42.5,47.5,50]$} & {$[45,47.5,52.5,55]$} \\
Larger & Large & Large large & Super large & Extreme large & Largest \\
{$[50,52.5,57.5,60]$} & {$[55,57.5,62.5,65]$} & {$[60,62.5,67.5,70]$} & {$[65,67.5,72.5,75]$} & {$[70,72.5,77.5,80]$} & {$[75,77.5,80]$} \\
\hline
\end{tabular}

Table 5: Quantified results for linguistic results

\begin{tabular}{lllllllll}
\hline Linguistic level & Smallest & Extreme small & Super small & Small small & Small & Smaller & Much smaller & A little smaller \\
\hline Defuzzification & 1.666667 & 5 & 10 & 15 & 20 & 25 & 30 & 35 \\
Medium & A little larger & Much larger & Larger & Large & Large large & Super large & Extreme large & Largest \\
40 & 45 & 50 & 55 & 60 & 65 & 70 & 75 & 78.33333 \\
\hline
\end{tabular}

The degree of membership for input (parameter) and output (attribute) can be described as shown in Table 3-4 respectively. Utilizing the average value of the fuzzy set to represent the entire set, we then have the quantified result for the fuzzy item of seventeen linguistic grades as shown in Table 5.

\section{RESULTS}

By considering the parameter combinations of the nine sets of experiment based on the $\mathrm{L}_{9}\left(3^{4}\right)$ orthogonal array, the quantified results from fuzzy deduction for the MRR are determined and shown as Table 6.
Introducing the deduction results as the Signal to Noise ratio $(\mathrm{S} / \mathrm{N})$ for $\mathrm{MRR}$ under larger-the-best expectation, the results of factor responses are calculated and listed in Table 7. The mean effects for $\mathrm{S} / \mathrm{N}$ ratios are then drawn by MINITAB 14 and shown as Fig. 2. Therefore, the optimum fuzzy deduction multi-attribute turning parameters are found to be A (High), B (High), C (High) and D (Low).

The finishing diameter turning operation of $\mathrm{S} 45 \mathrm{C}$ $(\varphi 45 \times 250 \mathrm{~mm})$ work piece on an ECOCA-3807 CNC lathe is arranged for the experiment. The TOSHIBA WTJNR2020K16 tool holder with MITSUBISHI NX2525 insert is utilized as the cutting tool. The four 
turning parameters (speed, cutting depth, feed rate and tool nose runoff) with three different levels (low, medium and high) are experimentally distinguished for the machining operation on the basis of $\mathrm{L}_{9}\left(3^{4}\right)$ orthogonal array. In Table 8, the three levels of speed, cutting depth and feed rate are identified from the machining handbook suggested by the tool manufacturer. The tool nose runoff is positioned by using different shims located under the tool holder and determined by measuring the tip after face turned the work piece. When the tool nose is set approximately 0.1 $\mathrm{mm}$ higher (lower) than the center of the work piece, it is regard as "High (Low)". When the tool nose is set within $\pm 0.03 \mathrm{~mm}$, it is considered as "Medium".

\section{DISCUSSION}

To verify the applicability of the optimum result achieved by our proposed deduction optimization technique, the machining operations under both fuzzy deduction optimization parameters and benchmark parameters; A (medium), B (medium), C (medium), D (medium), which are often introduced into the confirmation experiment in many of the studies (Tosun and Ozler, 2004; Lin and Lin, 2006) for comparison to the optimum parameters, are performed on the CNC lathe.

\begin{tabular}{ll} 
Table 6: Fuzzy deduction results & \\
\hline Attributes & MRR \\
experiment & 1.6667 \\
\hline 1 & 30 \\
2 & 65 \\
3 & 20 \\
4 & 55 \\
5 & 45 \\
6 & 45 \\
7 & 35 \\
8 & 70 \\
\hline
\end{tabular}

Table 7: Result of factor responses

\begin{tabular}{llllr}
\hline Parameter & & & & \\
level & $\mathrm{A}$ & $\mathrm{B}$ & $\mathrm{C}$ & $\mathrm{D}$ \\
\hline Low & 32.22 & 22.22 & 27.22 & 42.22 \\
Medium & 40.00 & 40.00 & 40.00 & 40.00 \\
High & 50.00 & 60.00 & 55.00 & 40.00 \\
Delta & 17.78 & 37.78 & 27.78 & 2.22 \\
Rank & 3.00 & 1.00 & 2.00 & 4.00 \\
\hline
\end{tabular}

Table 8: Parameters and levels

\begin{tabular}{lccc}
\hline Level parameter & $\begin{array}{l}\text { Low } \\
\text { (Level 1) }\end{array}$ & $\begin{array}{l}\text { Medium } \\
\text { (Level 2) }\end{array}$ & $\begin{array}{l}\text { High } \\
\text { (Level 3) }\end{array}$ \\
\hline A: speed (m/min) & 150.0 & 200.00 & 250.0 \\
B: cutting depth (mM) & 1.0 & 2.00 & 3.0 \\
C: feed rate (mm/rev) & 0.2 & 0.30 & 0.4 \\
D: tool nose runoff $(\mathrm{mm})$ & -0.1 & \pm 0.03 & 0.1 \\
\hline
\end{tabular}

Table 9: Confirmation results

\begin{tabular}{ll}
\hline & MRR \\
\hline Fuzzy Deduction (A3B3C3D1) & $0.0375 \mathrm{~mm}^{3} \mathrm{~min}^{-1}$ \\
Benchmark (A2B2C2D2) & $0.012 \mathrm{~mm}^{3} \mathrm{~min}^{-1}$ \\
\hline
\end{tabular}

The machined results are concluded and listed in Table 9. From Table 9, it is observed that the MRR under fuzzy deduction parameters is significantly improved by $212.50 \%$ from the benchmark parameters. It is shown that our proposed fuzzy deduction optimization technique can really advance the MRR for CNC turning.

\section{CONCLUSION}

In this study, the parametric deduction scheme was proposed and applied to achieve the optimum $\mathrm{CNC}$ finish turning parameters under the considerations of MRR. A confirmation experiment of the optimum deduction parameters was calculated to indicate the effectiveness of the proposed fuzzy deduction optimization method. Through the confirmation test, the experimental results validate the potency that the MRR can be advanced from our parametric deduction optimization technique.

Parametric optimization is a hard-solving issue. This study not only proposes a deduction optimization approach using orthogonal array, but also contributes the satisfactory fuzzy technique for improving the MRR in $\mathrm{CNC}$ turning with profound insight. The competition of manufacturing industry will then be economically excited through the proposed development in this study.

\section{ACKNOWLEDGEMENT}

Financial support for this study was provided by the National Science Council Taiwan, R.O.C., under the contract of NSC 98-2221-E-412-002.

\section{REFERENCES}

Gungor, Z. and F. Arıkan, 2007. Using fuzzy decision making system to improve quality-based investment. J. Intell. Manuf., 18: 197-207. DOI: 10.1007/s10845-007-0016-X

Haber, R.E., J.E. Jiménez, C.R Peres and J.R. Alique, 2004. An investigation of tool-wear monitoring in a high-speed machining process. Sensors Actuators A: Physical, 116: 539-545. DOI: 10.1016/j.sna.2004.05.017

Huh, H., J.H. Heo and H.W. Lee, 2003. Optimization of a roller leveling process for A17001T9 pipes with finite element analysis and Taguchi method. Int. J. Mach. Tool Manuf., 43: 345-350. DOI: 10.1016/S0890-6955(02)00269-9

Ismail, A.R., M.R.A. Rani, Z.K.M. Makhbul, K. Sopian and B.M. Deros, 2009. Thermal comfort assessment and optimization of environmental factors by using taguchi method. Am. J. Applied Sci., 6: 1731-1741. DOI: 10.3844/ajassp.2009.1731.1741 
Kaufmann, A. and M.M. Gupta, 1991. Introduction to Fuzzy Arithmetic Theory and Applications. 1st Edn., Van Nostrand Reinhold, New York, ISBN 0442230079, pp: 361.

Kim, S.J., K.S. Kim and H. Jang, 2003. Optimization of manufacturing parameters for a brake lining using Taguchi method. J. Mater. Process. Technol., 136: 202-208. DOI:10.1016/S09240136(03)00159-6

Kopac, J., 2002. Optimal machining for achieving the desired surface roughness in fine turning of cold pre-formed steel workpiece. J. Mach. Tool Manuf, 42: 707-716. DOI: 10.1016/S0890-6955(01)00163-8

Lan, T.S. and M.Y. Wang, 2009a. Competitive parameter optimization of multi-quality $\mathrm{CNC}$ turning. Int. J. Adv. Manuf. Technol., 41: 820-826. DOI: $10.1007 / \mathrm{s} 00170-008-1495-4$

Lan, T.S. and M.Y. Wang, 2009b. Quality prediction model of injection-molded rib design using back propagation network. Inform. Technol. J., 8: 847-854.

Lan, T.S., 2010. Parametric deduction optimization for surface roughness. Am. J. Applied Sci., 7: 1248-1253.

DOI: 10.3844/ajassp.2010.1248.1253

Lin, J.L. and J.F. Lin, 2006. Grey theory applied to evaluate the tribological performances of the a$\mathrm{CH}(\mathrm{N})$ coating films prepared by differing the nitrogen content and the film thickness. Int. J. Adv. Manuf. Technol., 27: 845-853. DOI: 10.1007/s00170-004-2294-1

Lin, W.S., B.Y. Lee and C.L. Wu, 2001. Modeling the surface roughness and cutting force for turning. J. Mater. Proc. Technol., 108: 286-293. DOI: 10.1016/S0924-0136(00)00835-9

Meng, Q., J.A. Arsecularatne and P. Mathew, 2000. Calculation of optimum cutting conditions for turning operations using a machining theory. Int. J. Adv. Manuf. Technol., 40: 1709-1733. DOI: 10.1016/S0890-6955(00)00026-2

Nalbant, M., H. Gökkayaa and G. Sura, 2007. Application of taguchi method in the optimization of cutting parameters for surface roughness in turning. Mat. Design, 28: 1379-1385. DOI: 10.1016/j.matdes.2006.01.008
Palanikumar, K., 2008. Application of Taguchi and response surface methodologies for surface roughness in machining glass fiber reinforced plastics by PCD tooling. Int. J. Adv. Manuf. Technol., 36: 19-27. DOI: 10.1007/s00170-0060811-0

Park, J.H., K.M. Yang and K.S. Kang, 2005. A quality function deployment methodology with signal and noise ratio for improvement of wasserman's weights. Int. J. Adv. Manuf. Technol., 26: 631-637. DOI: $10.1007 / \mathrm{s} 00170-003-2036-9$

Rao, R.V., 2006. Machinability evaluation of work materials using a combined multiple attribute decision-making method. Int. J Adv. Manuf. Technol., 28: 221-227. DOI: 10.1007/s00170-0042348-4

Ross, P.J., 1998. Taguchi Techniques for Quality Engineering. 2nd Edn., McGraw-Hill Publication New York, ISBN: 10: 0070539588, pp: 329.

Sukontanakarn, V. and M. Parnichkun, 2009. Realtime optimal control for rotary inverted pendulum. Am. J. Applied Sci., 6: 1106-1115. DOI: 10.3844/ajassp.2009.1106.1115

Tosun, N. and L. Ozler, 2004. Optimisation for hot turning operations with multiple performance characteristics. Int. J. Adv. Manuf. Technol., 23: 777-782. DOI: 10.1007/s00170-003-1672-4

Wei, H.S., S.C. Hwang and S.J. Liu, 2002. Analysis for the Optimum Conditions in Derrick Hook by Using Taguchi Method. Master Thesis, Nation Pingtung University of Science and Technology ROC.

Wu, F.C. and C.C. Chyu, 2002. A comparative study on Taguchi's SN ratio, minimising MSD and variance for nominal-the-best characteristic experiment. Int. J. Adv. Manuf. Technol., 20: 655-659. DOI: 10.1007/s001700200203

Zadeh, L.A., 1965. Fuzzy sets. Infor. Control., 8: 338-353. DOI: 10.1016/S0019-9958(65)90241-X

Zimmerman, H.J., 2001. Fuzzy Sets Theory and Its Applications. 4th Edn., Kluwer Academic Publisher Boston, ISBN: 9780792374350, pp: 544. 